its present unsatisfactory performance. Lack of community psychiatric nurses (CPNs), poor education and information regarding the CPA, confusion with Section 117 of the Mental Health Act 1983, lack of co-operation in inter-professional working and poor communication were the reasons given. The decision of keyworker status for CPNs continues to be synonymous with the "administration of depot anti-psychotic medication" so their other skills were not brought to bear fruit and their morale and interest lessened.

In contrast, the approved social workers (ASWs) and their manager felt they were given a keyworker status beyond "social work boundaries". They refused to accept this status, tending to categorise their skills. They agreed with the ethos and philosophy of the CPA which increased their awareness of lack of basic resources, ranging from sheltered accommodation to transport. Allocation of key-worker status to ASWs was frequently done in their absence, resulting in lack of communication and, in some instances, inappropriate allocation. Problems of inter-agency workings, understanding and cooperation were identified. These reflected conflict of different philosophical and cultural values.

CPA was perceived by consultant psychiatrists as almost insurmountable, even before the process of implementation. No change in clinical practice was observed. Several patients discharged from hospital or seen in other clinical settings were not assigned to a CPA, as there was a constant tendency to forget! Junior medical staff were not aware of the local CPA policy. The CPA was delayed or not discussed during multidisciplinary team meetings.

Staff nurses and ward clerks were diligent in completing the paperwork, not realising its importance. They expressed frustration that CPA was not instituted for a large number of patients. Patients and carers were not aware of the CPA despite their attendance at discharge plan meetings. When aware, they did not realise that such a system is a statutory policy within the provider-purchaser system.

DARRYL J.J. BRITTO and G. CRITChLOW, City General Hospital, Stoke-on-Trent ST4 6QG

\section{Community mental health care programme in Pakistan: new perspectives}

Sir: The organisation of mental health services in Pakistan is still at an elementary level and the care and management of the mentally ill is mostly provided in hospitals located in big cities. As most of the population live in rural areas and do not have easy access to these facilities, they turn naturally to spiritual and quasi-medical forms of treatment.
With the changing emphasis towards primary care in world psychiatry, mental health professional in Pakistan have also started thinking about changing existing mental health care systems. It was in this context that plans were made to decentralise mental health services and to integrate and collaborate with primary health care facilities, intending to make psychiatric services more acceptable and feasible at all levels. Basic health units and rural health centres have been chosen for provision of mental health care facilities and various programmes have been started by different departments of psychiatry in the country (Pakistan Psychiatric Society, 1988).

The Department of Psychiatry, King Edward Medical College, Lahore is contributing to these. A team comprising a psychiatrist, senior medical officer and a psychiatric social worker visits a rural health centre about $\mathbf{3 0}$ kilometres from the city of Lahore once a week. The team provides diagnostic, assessment and treatment facilities to those who attend the centre but also serves as a satellite clinic for admission and referrals to the nearest teaching hospital as need arises.

The experience of this service has shown very promising results to date. Comparison of this facility with existing psychiatric services in a general teaching hospital and a nearby mental hospital revealed that patients referred to these clinics were younger and had shorter duration of psychiatric lliness than those in hospitals (Javed \& Tareen, 1992). Similarly the diagnostic profiles of these patients hospital groups also showed that more cases of minor psychiatric illness were seen at rural health centres.

Like other reports, these findings appear to confirm the need for psychiatric services at the community level. There is no doubt that mental illnesses do exist in rural areas but the delays and difficulties in detection and diagnosis of psychiatric patients make the situation more complex. The results of 100 consecutive referrals to each of rural health centres, teaching hospitals, and mental hospitals showed that those coming to rural health centres were younger (mean 28.8) compared with 30.1 and 31.3, had shorter duration of illness (30.6 months) compared with 41.9 and 36.1 months and had a greater proportion with mood (30\%) and neurotic disorders $(31 \%)$ compared with $21 \%$ and $18 \%$ for mood disorder and $18 \%$ and $7 \%$ for neurotic disorder in two hospital groups.

Our results encourage the opening of similar facilities and strengthen the view that there is no need to open new big mental hospitals. Efforts should be made to create small units in the periphery and outreach mental health care programmes should be incorporated in the existing mental health care facilities (Hanfer, 1987).

Although treating mentally ill patients in the community has emerged as a major policy 
change in present day psychiatry (Griffiths, 1988), certain aspects of this programme need critical but constructive monitoring. It is true that provisions of psychiatric care at primary level do help in greater understanding of mental disorders and their management, but their cost effectiveness needs to be determined (Tyrer et al, 1986). This issue becomes even more important in countries like ours, where mental health care does not enjoy priority in health planning and consequently new plans are being formulated using limited financial resources.

GRIFFTHS, R. (1988) Communtty Care: agenda for action. London: HMSO.

HANFER. H. (1987) Do we still need beds for psychiatric patients? Acta Psychiatrica Scandinavica, 75, 113-126.

JAVED, M.A. \& TAREEN, I.A.K. (1992) Community based mental health care programme. The Paktstan Journal of Clinical Psychtatry 1, 127-132.

Pakistan Psychiatric Society (1988) Psychiatry in Paktstan (Ed. S. Haroon Ahmad) Karachi: Pakistan Psychiatric Society.

TYRER, P., GILL, D. \& FARR, P. (1986) Cost of community psychiatry. British Journal of Psychiatry, 149, 795-796.

Mohammad AFzal JAVEd, and I. A. K. TAREen, King Edward Medical College/Mayo Hospital, Lahore, Pakistan

\section{People with learning disabilities: resettlement issues}

Sir: The resettlement of people with learning disabilities continues in earnest. Between 1981 and 1990, the estimated number of people resettled in England, Wales and Northern Ireland was 13,861, 436 and 232 respectively (Glover et al, 1993). The current hospital population comprises people with severe learning disabilities and superimposed behavioural/psychiatric conditions, profound and multiple physical handicaps and the frail elderly. They need 24 hour supervision and care by trained and experienced staff. Cochran et al (1977) identify preparatory steps which can minimise the distress of relocation syndrome.

Recently we resettled three elderly residents into a well-planned purpose-built, non-health authority accommodation in the community. Despite detailed and repeated exchange of information, one of the clients died a few days after discharge having sustained severe scalds in the bath. The following points emerged.

(a) Although the client was living in community, the press continued referring to him as a hospital patient. This highlights the sensitive nature of the resettlement of this vulnerable group and the need for the consultant to continue asserting a central role in planning the discharge.

(b) The lack of adequate training and expertise, coupled with ideological adherence to principles of normalisation, prevented the community staff from understanding and accepting the client needs. Important information given by the ward staff was rejected as 'negative attitudes'.

(c) The importance of written and well documented detailed exchange of information between hospital and community staff.

(d) A need for enhanced ownership of resettlement principles and policies by ward staff. In the present climate of change and unpredictability, the staff need plenty of support and encouragement.

Resettlement of a residual hospital population with learning disabilities requires a sensitive, compassionate and a well balanced approach based on sound research and experience rather than ideological concepts. The medical audit which is now an integral part of clinical practice offers an excellent opportunity to address the points highlighted.

COCHRAN et al (1977) The relocation syndrome in mentally retarded individuals. Mental Retardation. 16, 10-12.

GLOVER et al (1993) Is the money following the clients with learning disabilities? BMJ, 306, 987-990.

H. M. VERMA, Brynhyfryd Hospital, Forden, Near Welshpool, Powys SY21 8NW

\section{Use of section 4 Mental Health Act 1983}

Sir: The use of section 4 is being discouraged to such an extent that, even in situations where it is valid, demands are made for implementation of section 2. Such a situation arose recently in spite of advice to use section 4 by the senior doctor on call to the approved social worker. The patient was reported to be disturbed and verbally aggressive to his parents. The on-call GP happened to be a trainee with little experience of such patients. The social worker had no knowledge of the patient and his family. The patient had a learning disability and epilepsy and was known to the learning disability team of local social services. A decision to use section 2, rather than section 4, was made. A section 12 approved doctor was called, who had no knowledge of the patient, but he supported the section 2 for admission. Soon after admission the consultant psychiatrist, nursing staff, the patient's regular social worker and community nurse, and members of the learning disability team, discussed the circumstances of admission. It was felt that the patient had no problems of behaviour, mental illness or valid reason for admission on section 2 or 4. A social worker or community nurse with learning disability experience could have easily prevented the admission.

This case is of concern as even though the section 2 used was legally correct none of the professionals involved knew the patient or his family and yet used section 2 for admission 